\title{
Induction of Antibodies Specific for Gp41 of HIV-1 by Gene Gun DNA Vaccination
}

Rayk Behrendt, Uwe Fiebig, Mirco Schmolke, Reinhard Kurth and Joachim Denner*

Robert Koch Institute, Berlin, Germany

\begin{abstract}
All attempts to induce broadly neutralising antibodies such as mAb 2F5 and mAb 4E10 targeting conserved epitopes in the membrane proximal external region (MPER) of the transmembrane envelope (TM) protein gp41 of HIV-1 failed so far. In contrast, in previous studies, immunising with the ectodomain of the TM protein p15E of different gammaretroviruses, we successfully induced neutralising antibodies. These antibodies recognised epitopes located in the fusion peptide proximal region (FPPR) and in the MPER of p15E. The epitope in the MPER of p15E corresponds to that of the mAb 4E10 in gp41 in terms of location within the protein and partial sequence homology. In order to present the MPER of gp41 (containing the 2F5 and 4E10 epitopes) membrane-associated, rats were immunised with DNA constructs corresponding (i) to the entire gp41, (ii) to the C-terminal helix of gp41 and (iii) to hybrid proteins composed of a backbone derived from p15E of a gammaretrovirus with inserted FPPR and MPER from gp41 of HIV-1. After transfection in vitro these proteins were found expressed at the cell surface and the accessibility of the $2 \mathrm{~F} 5$ epitope was demonstrated by flow cytometry. However, DNA vaccination in rats resulted only in low titres of antibodies specific for the MPER of HIV-1, and none of the sera was neutralising.
\end{abstract}

Keywords: HIV-1; gP41; MPER; FPPR; DNA vaccination; Gene gun

\section{Introduction}

Eliciting broadly neutralising antibodies against the human immune deficiency virus 1 (HIV-1) is still considered to be an inevitable goal of HIV vaccine research. Because of the variability of its envelope proteins the conserved domains of these proteins represent a good potential target for broadly neutralising antibodies. One of these conserved domains is the membrane proximal external region (MPER) of the transmembrane envelope (TM) protein gp41 of HIV-1. Two of the most potent broadly neutralising antibodies against HIV-1, mAb 2F5 and mAb 4E10 bind to epitopes located in the MPER of gp41 [1,2]. This domain was considered to be an excellent target region for vaccine development [3]. However, numerous immunisation studies using proteins containing the epitopes of $\mathrm{mAb} 2 \mathrm{~F} 5$ and $\mathrm{mAb} 4 \mathrm{E} 10$ failed to induce broadly neutralising antibodies so far $[4,5]$.

In contrast to the situation with HIV-1, neutralising antibodies against different gammaretroviruses such as porcine endogenous retrovirus [6,7], feline leukaemia virus [8-10] and Koala retrovirus [11] have been easily induced by immunisation with the recombinant ectodomains of their TM proteins. The epitopes recognised by the immune sera were located in the $\mathrm{N}$-terminal fusion peptide proximal region (FPPR) and in the C-terminal MPER of p15E. The MPER of PERV, FeLV and KoRV is homologous to that of gp41 of HIV-1 and despite the evolutionary distance between gammaretroviruses and HIV-1 a limited sequence homology of the epitopes was identified [611] (Figure 1a).

When studying the mechanisms of neutralisation by mAb 2F5 and $\mathrm{mAb} 4 \mathrm{E} 10$, complex coherences between the structure of the MPER and antibody binding were observed [12-14]. Interaction of both antibodies with lipids, their long hydrophobic CDR3 loop and cross-reactivity with cardiolipin have been discussed controversially as possible reasons for the failure of all previous immunisation attempts [15-17]. Since there is evidence for intramolecular interactions between the MPER and the FPPR during infection and neutralisation [18-22] and a peptide corresponding to the sequence of the FPPR has been shown to increase binding of $\mathrm{mAb} 2 \mathrm{~F} 5$ to its epitope [14], it was suggested that the FPPR a)

\begin{tabular}{cccc} 
retrovirus & amino acid sequence of the MPER & \% matching aa with HIV-1 & reference \\
\hline FeLV & LRERLKQRQQLFDSQQGWFEGWFNKSPWF & $20,70 \%$ & M18247 \\
PERV & LRERLERRRREREADQGWFEGWFNRSPWM & $24,10 \%$ & AY953542 \\
KoRV & LKERLDKRQLEHQRNLSWYEGWENRSPWL & $34,50 \%$ & DQ174772 \\
HIV-1 & QQERNEQELLELDKWAS-LWNWENITNWL & - & AF324493 \\
\hline
\end{tabular}

b) gP41 $512 \mathrm{~N} /$ FP/FPPR gp41-CHR Hyb1

Hyb2

Hyb2
Hyb3

Hyb3
Hyb4

Hyb5

Hvb6

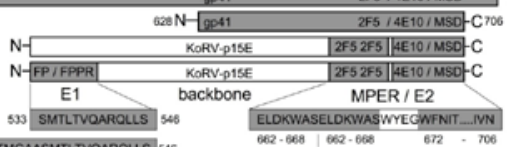

Figure 1: (a) Alignment of the amino acid sequences of the MPER of $\mathrm{p} 15 \mathrm{E}$ of FeLV, PERV and KoRV and gp41 of HIV-1, identical amino acids are bold (b) Schematic presentation of the antigens used in this study. Amino acid sequences derived from p15E of KoRV (DQ174772) are shown in white boxes and amino acid sequences derived from gp41 of HIV-1 (AF324493) are shown in grey boxes. Numbering below the drawings refers only to the amino acid sequence of gp41. The drawings are not in scale. FP-fusion peptide FPPR-fusion peptide proximal region, MPER- membrane proximal external region, MSD-membrane spanning domain.

may be required to generate a conformation which will be able to induce broadly neutralising antibodies of the $2 \mathrm{~F} 5$ and $4 \mathrm{E} 10$.

Enhanced binding of $\mathrm{mAb} 2 \mathrm{~F} 5$ and $\mathrm{mAb} 4 \mathrm{E} 10$ to their epitopes was observed in a lipid environment compared with free MPER peptides [23-26]. These findings raise the question, whether membranes or

*Corresponding author: Dr. Joachim Denner, Robert Koch Institute, Nordufe 20, D-13353 Berlin, Germany, Tel: +49 3018745 2800; Fax: +49 3018745 2801; E-mail: DennerJ@rki.de

Received June 18, 2012; Accepted August 16, 2012; Published August 22, 2012

Citation: Behrendt R, Fiebig U, Schmolke M, Kurth R, Denner J (2012) Induction of Antibodies Specific for Gp41 of HIV-1 by Gene Gun DNA Vaccination. J Vaccines Vaccin 3:145. doi:10.4172/2157-7560.1000145

Copyright: @ 2012 Behrendt R, et al. This is an open-access article distributed under the terms of the Creative Commons Attribution License, which permits unrestricted use, distribution, and reproduction in any medium, provided the original author and source are credited. 


\begin{tabular}{|c|c|}
\hline Primers/probes & Primer sequence $\left(5^{\prime}-3^{\prime}\right)$ \\
\hline MSD1-rev & tatgaataattttatataccacagccaatttgttatgttgaaccatcc \\
\hline MSD2-rev & tcttaaacctaccaagcctcctactatcattatgaataattttat \\
\hline MSD3-rev & ctgctgcagtcaattcactatagaaagtacagcaaaaactattcttaaacctaccaagc \\
\hline E1-for & $\begin{array}{l}\text { gcgggatccacgagcatgacactaacagtgcaggcacgccaactactatcttgact } \\
\text { agcctccagatt }\end{array}$ \\
\hline Hyb3-for & cgggatccagcactatgggcgcagcgtcagtgacgctgacggtacag \\
\hline Hyb4-for & cgggatccttaggagcagcaggaagcactatgggcgcagcg \\
\hline Hyb5-for & cgggatccctgttccttgggttcttaggagcagcaggaagc \\
\hline Hyb6-for & cgggatccgcagcgataggagctctgttccttgggttctta \\
\hline gp41-for & ccagatctgcagtgggaataggagctttgttccttggg \\
\hline gp41-rev & cctgagctgcagataccacagccaatttgttatg \\
\hline CHR-for & gaagatctatggagtgggacagagaaattaac \\
\hline CHR-rev & cctgagctgcagataccacagccaatttgttatg \\
\hline hGAPDH-for & ggcgatgctggcgctgagtac \\
\hline hGAPDH-rev & tggtccacacccatgacga \\
\hline hGAPDH-probe & Hex-ttcaccaccatggagaaggctggg-BHQ-1 \\
\hline $68 \mathrm{i}$ & ggarcagciggaagcaciatgg \\
\hline $69 i$ & ccccagacigtgagiticaaca \\
\hline HIV-1-probe & FAM-tccgetgggccatcctggaggctc-BHQ-1 \\
\hline T7-prom & taatacgactcactataggg \\
\hline
\end{tabular}

Table 1: Primers and probes used for the generation of constructs and for rea time PCR.

lipids are required for the induction of such neutralising antibodies. One way to present the MPER of gp41 in a natural lipid environment is DNA vaccination allowing the MPER to be associated with the cell membrane. Although DNA vaccination was mainly used for induction of MHC-I specific cytotoxic cellular immune responses, it can also be used for the induction of humoral immune responses [27-30].

In this study, DNA constructs corresponding to the entire ectodomain of gp41, to the C-helical region of gp41 (gp41-CHR) as well as to hybrid constructs containing a gammaretrovirus backbone and sequences of the epitopes of mAb 2F5 and mAb 4E10 together with the FPPR were used in gene gun immunisation studies. Expression of gp41 and the hybrid antigens on the cell surface was demonstrated in vitro, and after immunisation of rats antibodies specific for gp41 were found. These findings may help to develop new strategies for a cell membrane-associated presentation of potential HIV vaccines in order to induce neutralising antibodies against conserved domains in gp41.

\section{Materials and Methods}

\section{Generation of the antigen-coding constructs}

The sequences of gp41-CHR and gp41 (Figure 1) were amplified by PCR (primers: CHR-for and CHR-rev; gp41-for and gp41-rev) (Table 1) using the HIV-1 molecular clone pNL4-3 (AF324493) as a template. The hybrid sequences were generated by mutagenesis PCR using primers partly homologous to the KoRV-p15E sequence (DQ174772) and providing the HIV-1 gp41 specific sequences derived from pNL43. The sequence of hybrid 1 (Hyb1) was generated by three sequentially performed PCRs using (i) primers T7-prom and MSD-1-rev on the template of pCal-n-KoRV-p15E [11], (ii) primers T7-prom and MSD2-rev on the template generated in step (i), (iii) primers T7-prom and MSD-3-rev on the template generated in step (ii). The sequence of Hyb2 was generated using Hybl as template and performing mutagenesis PCR with the primers E1-for and MSD-3-rev. The hybrids Hyb3 to Hyb6 were generated similarly combining the reverse primer MSD3-rev with the desired forward primers Hyb3-for, Hyb4-for, Hyb5-for and Hyb6-for (Table 1 and Figure 1). All PCRs were performed under the following conditions: $95^{\circ} \mathrm{C} / 10 \mathrm{~min}, 35$ cycles: $95^{\circ} \mathrm{C} / 45 \mathrm{~s} ; 42^{\circ} \mathrm{C} / 120$ s; $72^{\circ} \mathrm{C} / 45$ s, final extension: $72^{\circ} \mathrm{C} / 10$ min using the AmpliTaq Gold (Applied Biosystems, Foster City, USA). All PCR products were cloned into the eukaryotic surface expression vector pDisplay (Invitrogen, Karlsruhe, Germany) using the restriction sites BglII and PstI. The correctness of the reading frames were confirmed by sequencing. Plasmids were purified using the Endo-Free-Maxi Prep Kit (Qiagen, Hilden, Germany).

\section{Transfection of Rat-1 cells}

Lipofectamine 2000 reagent (Invitrogen, Karlsruhe, Germany) was used according to the manufactures instructions. $2 \times 10^{5} / \mathrm{ml}$ Rat-1 cells were seeded into a 6-well cell culture plate and transfected with $5 \mu \mathrm{g}$ endotoxin-free plasmid when $80 \%$ cell confluence was reached. After 48 hours cells were transferred into DMEM containing $600 \mu \mathrm{g} / \mathrm{ml}$ geneticin (Invitrogen, Karlsruhe, Germany) in order to generate stably transfected cell lines.

\section{Flow cytometry}

Stably transfected Rat-1 cells were detached from the culture flask bottom using a cell scraper and washed three times with $10 \mathrm{ml}$ of ice cold PBS. The cells were blocked for $30 \mathrm{~min}$ in ice cold PBS containing 10\% (v/v) fetal bovine serum. mAb 2F5 $(10 \mu \mathrm{g} / \mathrm{ml})$ was added in blocking buffer. After incubation for $30 \mathrm{~min}$ on ice the cells were washed three times with ice cold PBS, and FITC-labelled secondary anti-human IgG antibodies (1:1000, Sigma, Munich, Germany) were added. Cells were incubated in the dark for $30 \mathrm{~min}$ on ice and then washed five times with PBS. Finally, 2\% (v/v) formaldehyde (Roth, Karlsruhe, Germany) in PBS was added to fix the cells. Surface expression was assayed in a FACSCalibur cytometer (BD, Franklin Lakes, USA). Data were analysed using the CellQuest Pro software (BD, Franklin Lakes, USA).

\section{DNA immunisation}

Endotoxin-free plasmids were precipitated onto gold particles (particle $\varnothing 0.9 \mu \mathrm{m}, 2.5 \mu \mathrm{g}$ DNA/1mg gold). The coated particles were inoculated into the shaved abdominal skin of 4 weeks old Wistar rats (Charles River) using the Helios Gene Gun ${ }^{\star}$ (Bio Rad, Munich, Germany) with a helium impulse at 400 psi. Each rat received a triple application $(1 \mu \mathrm{g} / \mathrm{shot})$. Boost immunisations using the same procedure were performed on days 14 and 28 post primary immunisation.

\section{ELISA}

Peptide ELISAs were performed as described elsewhere [31]. $200 \mathrm{ng} /$ well of the FPPR-derived peptide (aa524-547) (GAAGSTMGAASVTLTVQARLLLS) or the MPER-derived peptide (aa655-679) (NEQELLELDKWASLWNWFDITNWL) (JPT, Berlin, Germany) was coated on Nunc immunoplates (Nunc, Denmark) over night at $37^{\circ} \mathrm{C}$. Sera were diluted 1:350 in blocking buffer. To detect antibodies specific for gp41 or KoRV p15E, purified recombinant gp41 (aa530-683, reference K03455, 400 ng/well) and recombinant KoRV p15E (aa489-597, reference DQ174772, $200 \mathrm{ng} /$ well) [11] were diluted in water and coated over night at $37^{\circ} \mathrm{C}$.

\section{Neutralisation assay}

A newly developed neutralisation assay based on the measurement of reduction of provirus integration as a marker for neutralisation was used [14,32]. Briefly: a $20 \mu \mathrm{l}$ serum dilution and $80 \mu \mathrm{l} \mathrm{HIV-}$ $1_{\text {IІІв }}\left(\mathrm{TCID}_{50}=10^{3} / \mathrm{ml}\right)$ were incubated for $30 \mathrm{~min}$ at $37^{\circ} \mathrm{C} / 5 \% \mathrm{CO}_{2}$. C8166 cells $(5 \times 104$ cells in $100 \mu \mathrm{l})$ were added and after 65 hours the supernatant was aspirated. Then cells were lysed and provirus integration was determined by an HIV-1 specific duplex real-time PCR 


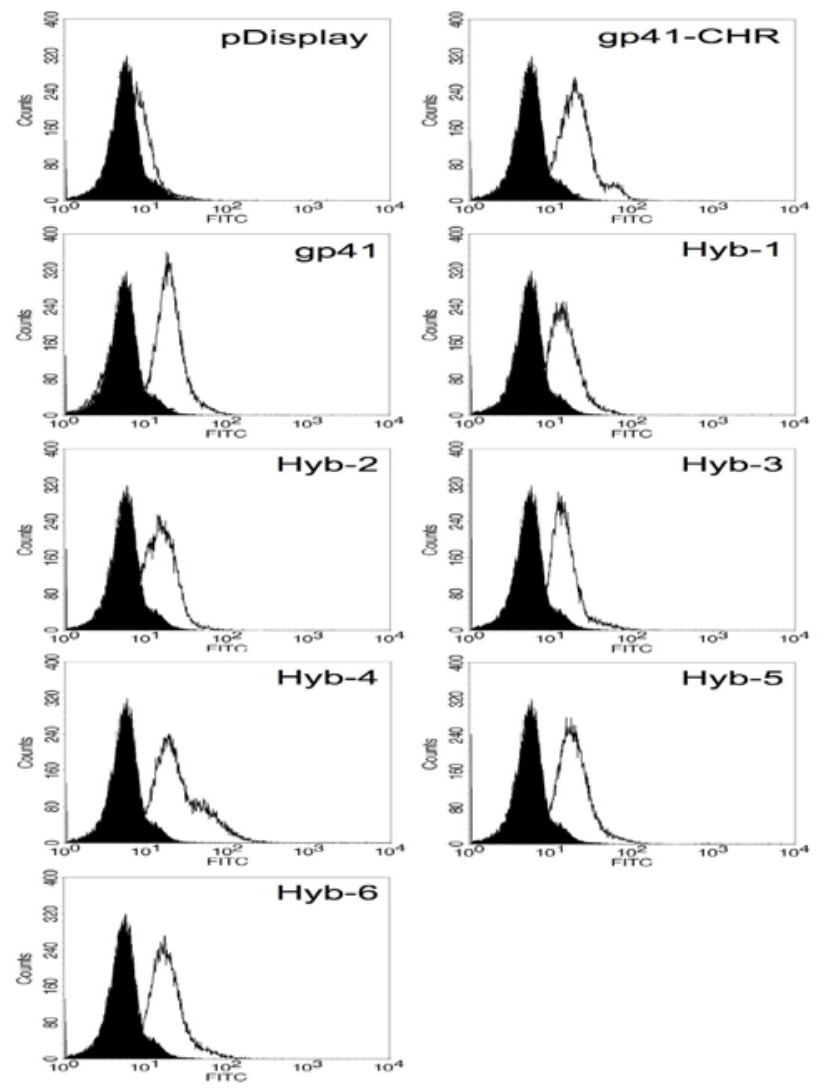

Figure 2: Analysis of surface expression of gp41, gp41-CHR and 6 hybrid proteins after transfection of the corresponding DNA vaccines by flow cytometry (black-untreated Rat-1 cells, white-stable transfected Rat-1 cells, pDisplay-cells transfected with the empty vector). Antigens were detected using mAb 2F5 and stained with FITC-labeled anti-human-IgG.

using the HIV-1 specific primers $68 \mathrm{i}$ and $69 \mathrm{i}$ [33] as well as an HIV1-probe (Table 1). To analyse toxic effects of the sera, simultaneously the amount of GAPDH genes (primers: hGAPDH-for and hGAPDHrev, probe: hGAPDH-probe, Table 1) was analysed. For amplification the real-time cycler MX-4000 (Stratagene, La Jolla, USA) was used with the following cycling conditions: $95^{\circ} \mathrm{C} / 8 \mathrm{~min}+50$ cycles: $95^{\circ} \mathrm{C} / 45$ s- $55^{\circ} \mathrm{C} / 60 \mathrm{~s}-72^{\circ} \mathrm{C} / 20 \mathrm{~s}$. Neutralisation (NT) was calculated using the formula: $\mathrm{NT}=100-100 / 2 \Delta \Delta \mathrm{Ct}$. A reduction of $75 \%$ provirus integration $(\Delta \mathrm{Ct}=2)$ was defined as significant neutralisation. As positive control $\mathrm{mAb} 2 \mathrm{~F} 5(5 \mu \mathrm{g} / \mathrm{ml})$ was used.

\section{Results}

DNA immunisation with gp41 and the CHR domain of gp41

DNA constructs, corresponding to the entire gp41 and to the CHR domain of gp41 (gp41-CHR), were generated (Figure 1b). To study expression of the encoded proteins on the cell surface in vitro, stable transfected Rat-1 cells were analysed by flow cytometry using mAb 2F5 (Figure 2). Fluorescence signals were detected with all transfected cell lines compared to untreated Rat-1 cells. Since the cells were not permeabilised, the observed staining indicated cell surface expression of all constructs as well as accessibility of the epitope of 2F5 when presented in such a way. Rats were immunised using these DNA constructs as described in Materials and methods. 14 days after the third immunisation, sera were taken and screened for binding antibodies in an ELISA. In nearly all sera (except serum from rat no. 6), gp41 specific antibodies were detected (Table 2). The highest titre $(1: 64,000)$ of gp41 specific binding antibodies was found in the sera from rats 9 to 12, immunised with a DNA construct corresponding to the entire gp41. Sera obtained by DNA immunisation with the gp41CHR construct showed a titre of gp41-binding antibodies of 1:8,000. When analysed for neutralising activity, none of the gp 41 specific sera generated by DNA immunisation was able to neutralise HIV-1 $1_{\text {IIIB }}$ (Figure 3 ).

\section{Design of DNA constructs corresponding to TM hybrid proteins}

Since DNA immunisation with the entire sequence of gp41 or the CHR of gp41 in a membrane-bound context did not induce neutralising antibodies, a new strategy for antigen design was developed. The sequence, corresponding to the epitopes of mAb $2 \mathrm{~F} 5$ and $\mathrm{mAb} 4 \mathrm{E} 10$, and the sequence in the FPPR able to increase binding of mAb2F5 and $\mathrm{mAb} 4 \mathrm{E} 10$ to their epitopes [14] were inserted into the TM protein $\mathrm{p} 15 \mathrm{E}$ of KoRV. p15E was used as a backbone and from this backbone the regions in the MPER and FPPR shown to contain epitopes recognised by antibodies neutralising KoRV were replaced by the gp41-specific MPER and FPPR domains (Figure 1b). We expected that the helical regions of $\mathrm{p} 15 \mathrm{E}$ of KoRV will bring the MPER and FPPR derived from gp41 of HIV-1 in close proximity generating a conformation which allows inducing broadly neutralising antibodies.

\section{DNA immunisation with DNA constructs corresponding to} TM hybrids

To demonstrate the expression of the TM hybrid proteins, encoded

\begin{tabular}{|c|c|c|c|c|}
\hline Rat no. & Construct & Titre gp41 & E1 & E2 \\
\hline $\begin{array}{l}1 \\
2 \\
3 \\
4\end{array}$ & pDisplay & $\begin{array}{l}- \\
- \\
- \\
-\end{array}$ & $\begin{array}{l}0.0 \\
0.0 \\
0.0 \\
0.0\end{array}$ & $\begin{array}{l}0.0 \\
0.0 \\
0.0 \\
0.0\end{array}$ \\
\hline $\begin{array}{l}5 \\
6 \\
7 \\
8\end{array}$ & gp41-CHR & $\begin{array}{c}1: 8000 \\
- \\
1: 8000 \\
1: 8000\end{array}$ & $\begin{array}{l}0.0 \\
0.0 \\
0.0 \\
0.0\end{array}$ & $\begin{array}{c}0.08 \\
0.0 \\
0.10 \\
0.10\end{array}$ \\
\hline $\begin{array}{c}9 \\
10 \\
11 \\
12\end{array}$ & gp41 & $\begin{array}{l}1: 64000 \\
1: 64000 \\
1: 64000 \\
1: 64000\end{array}$ & $\begin{array}{l}0.32 \\
0.59 \\
0.29 \\
0.37\end{array}$ & $\begin{array}{l}0.42 \\
0.51 \\
0.37 \\
0.46\end{array}$ \\
\hline $\begin{array}{l}13 \\
14 \\
15 \\
16\end{array}$ & Hyb1 & $\begin{array}{l}1: 4000 \\
1: 4000 \\
1: 4000 \\
1: 4000\end{array}$ & $\begin{array}{l}0.0 \\
0.0 \\
0.0 \\
0.0\end{array}$ & $\begin{array}{l}0.08 \\
0.08 \\
0.09 \\
0.06\end{array}$ \\
\hline $\begin{array}{l}17 \\
18 \\
19 \\
20\end{array}$ & Hyb2 & $\begin{array}{l}1: 4000 \\
1: 4000 \\
1: 4000 \\
1: 4000\end{array}$ & $\begin{array}{c}0.150 .12 \\
0.18 \\
0.20\end{array}$ & $\begin{array}{l}0.06 \\
0.06 \\
0.09 \\
0.09\end{array}$ \\
\hline $\begin{array}{l}21 \\
22 \\
23 \\
24\end{array}$ & Hyb3 & $\begin{array}{l}1: 4000 \\
1: 8000 \\
1: 4000 \\
1: 4000\end{array}$ & $\begin{array}{l}0.25 \\
0.42 \\
0.29 \\
0.27\end{array}$ & $\begin{array}{l}0.08 \\
0.08 \\
0.09 \\
0.03\end{array}$ \\
\hline $\begin{array}{l}25 \\
26 \\
27 \\
28\end{array}$ & Hyb4 & $\begin{array}{l}1: 4000 \\
1: 4000 \\
1: 4000 \\
1: 4000\end{array}$ & $\begin{array}{l}0.34 \\
0.30 \\
0.15 \\
0.29\end{array}$ & $\begin{array}{l}0.07 \\
0.09 \\
0.10 \\
0.08\end{array}$ \\
\hline $\begin{array}{l}29 \\
30 \\
31 \\
32\end{array}$ & Hyb5 & $\begin{array}{l}1: 4000 \\
1: 4000 \\
1: 4000 \\
1: 8000\end{array}$ & $\begin{array}{l}0.18 \\
0.25 \\
0.07 \\
0.31\end{array}$ & $\begin{array}{l}0.06 \\
0.08 \\
0.08 \\
0.11\end{array}$ \\
\hline $\begin{array}{l}33 \\
34 \\
35 \\
36\end{array}$ & Hyb6 & $\begin{array}{l}1: 4000 \\
1: 8000 \\
1: 4000 \\
1: 4000\end{array}$ & $\begin{array}{l}0.10 \\
0.44 \\
0.24 \\
0.41\end{array}$ & $\begin{array}{l}0.09 \\
0.09 \\
0.08 \\
0.04\end{array}$ \\
\hline
\end{tabular}

Table 2: ELISA analysis: gp41 specific binding antibodies (OD 492nm/620nm) induced by immunization with different antigens. 


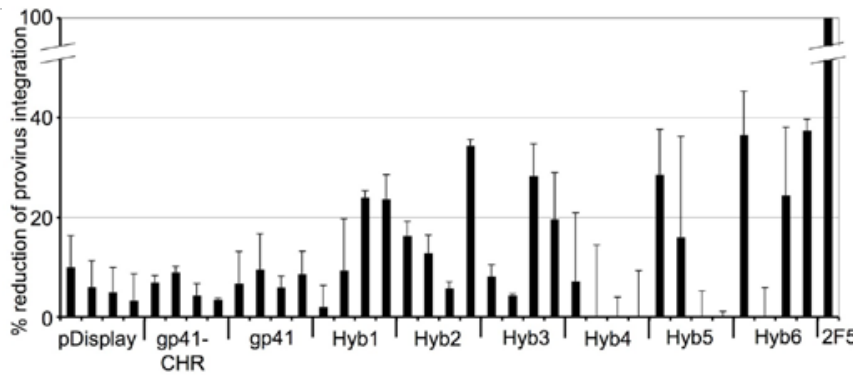

Figure 3: Results of the neutralisation assays using HIV-1IIIB and antisera induced in rats by DNA immunisation with different constructs as shown in Figure 1. MAb 2F5 was used as positive control. Each value is the result of a triplicate measurement. Significant neutralisation was defined as reduction of provirus integration above $75 \%$.

by the DNA constructs described above, each of the six hybrid proteins (Hyb1-Hyb6) was transfected into Rat-1 cells and stable transfected lines were generated. Flow cytometry analysis of these cell lines using $\mathrm{mAb} 2 \mathrm{~F} 5$ showed surface expression and accessibility of the 2F5 epitope in all cases (Figure 2). All six DNA constructs were used for DNA immunisation, as described in Material and methods, and the induced sera were analysed in ELISAs. Only low titres of antibodies specific for synthetic peptides corresponding to the FPPR and MPER of gp41 were found (Table 2). As a rule, the responses against the FPPRderived peptide were stronger, compared with the responses against the MPER-derived peptide. To study the presence of neutralising antibodies in the immune sera, HIV-1IIIB was used in a real-time PCR-based neutralisation assay measuring provirus integration. This assay gave similar results when compared with the TZM-bl cell based assay and has numerous advantages [32]. Such neutralisation assays have been used to screen for neutralising antibodies specific for PERV [7], FeLV [8], KoRV [14] and HIV-2 [31]. None of the sera induced by DNA immunisation with the DNA hybrid constructs was able to reduce provirus integration of HIV-1IIIB (Figure 3).

\section{Determination of antibodies directed against the p15E backbone}

Since the antibodies induced by DNA immunisation using the hybrid constructs Hyb1-Hyb6 were not neutralising HIV-1 (Figure 3 ), the reactivity of the sera was analysed in more detail. To study the presence of antibodies specific for the p15E backbone, an ELISA using recombinant $\mathrm{p} 15 \mathrm{E}$ of KoRV was performed. In all sera from rats immunised with DNA hybrid constructs antibodies against the p15E backbone were detected. This was rather astonishing, because after immunisation with $\mathrm{p} 15 \mathrm{E}$ of different gammaretroviruses including KoRV, mainly antibodies against the FPPR and the MPER, but not against other parts of p15E were detected [6-10]. Surprisingly, sera from untreated control rats and from rats immunised with gp41 or gp41-CHR DNA constructs also contained antibodies against p15E of KoRV (Figure 4). These data indicate that in contrast to previous experiments antibodies against $\mathrm{p} 15 \mathrm{E}$ of a gammaretrovirus were found in naïve Wistar rats not yet used for immunisation. The preformed antibodies against the p15E backbone may have interfered with the immune response against the hybrid protein containing FPPR-derived and MPER-derived from gp41 of HIV-1. This finding may partially explain the low titre of antibodies against the inserted HIV-1 sequences.

\section{Discussion}

Immunisation of rats with DNA constructs corresponding to gp41, to the C-terminal helix of gp41 (gp41-CHR) or to hybrid proteins composed of a backbone derived from $\mathrm{p} 15 \mathrm{E}$ of the gammaretrovirus KoRV and the FPPR and MPER of gp41 of HIV-1 failed to induce neutralising antibodies. This new vaccination strategy was developed based on some recent findings: First, since immunising with p15E of different retroviruses was successful [6-11], hybrids were used because we expected that the helical regions of $\mathrm{p} 15 \mathrm{E}$ bring the MPER and the FPPR of HIV-1, which substituted the FPPR and MPER of PERV, into close proximity, and the antigen may be able to induce neutralising antibodies. Second, a DNA immunisation approach was used to gain a membrane-associated localisation of the MPER expecting that it will be able to induce neutralising antibodies such as mAb $2 \mathrm{~F} 5$. However, this approach failed despite the cell surface localisation of the expressed $\mathrm{p} 41$ or gp41-CHR was shown.

We recently identified a domain in the FPPR of gp41 that was able to enhance binding of mAb $2 \mathrm{~F} 5$ and $\mathrm{mAb} 4 \mathrm{E} 10$ to their epitopes in the MPER [14]. Other authors had shown an interaction between MPER and FPPR during infection [18-22]. These findings suggested that the interaction between the MPER and the FPPR during infection may generate a conformation able to induce 2F5/4E10-like neutralising antibodies. However, all DNA constructs failed to induce antibodies significantly neutralising HIV-1 (Figure 3).

In other studies, the epitope sequence of $2 \mathrm{~F} 5$ was added to the C-terminal part of $\mathrm{p} 15 \mathrm{E}$ of PERV displayed on vesicular stomatitis virus particles in a membrane bound context [34] or as a rhinovirus hybrid [35] or in a pre-fusion state expressed on the surface of immature viruslike particles from Sf9 cells [36]. Only low, if any, titres of neutralising antibodies were observed. Wang et al. [37] reported the induction of neutralising antibodies after immunisation with a protein containing the CHR, NHR and the MPER, which recognised an epitope in the MPER. Immunising guinea pigs with DNA or VLP based on a HA/gp41 protein with a mutated Cys in the HA subunit, Ye et al. [38] reported a neutralising activity which could be blocked with a MPER-specific peptide, thus demonstrating induction of MPER-specific neutralising antibodies. Using a phage library, an HIV-1 elite controller was identified who developed antibodies against the MPER and neutralising antibodies were induced when immunising with the epitope phage [39]. Neutralising antibodies were also induced when using the epitope and synthetic sequential carriers or a palmitoyl group. On the other hand, immunising with VLP expressing the MPER Kandem Toukam et al. [40] were able to induce MPER-specific antibodies binding the 2F5 epitope, but not neutralising. A conformation-specific display of $4 \mathrm{E} 10$ and 2F5 epitopes on self-assembling protein nanoparticles also failed to induce neutralising antibodies [41].

There may be several reasons for the failure of many of the attempts to induce 2F5/4E10-like neutralising antibodies including our new approach: First, although it has been shown, that peptides derived from the FPPR increase the binding of mAb 2F5 to its epitope in the MPER/ E2 domain [14] and there is an interaction between MPER and FFPPR [18-22], it is still unknown whether this interaction is also required for the induction of 2F5/4E10-like broadly neutralising antibodies. Second, it remains unclear, whether the DNA immunisation generated the correct membrane associated context. HIV particles are budding from special regions of the cell membrane, so called rafts, that are characterised by specific lipid content [42] and it is unclear whether the DNA vaccines were also expressed in such a compartment. Third, conformational restrictions in the antigens expressed in vivo may have prevented the induction of neutralising antibodies. Fourth, pre-existing antibodies directed against the p15E backbone (Figure 4) may have 


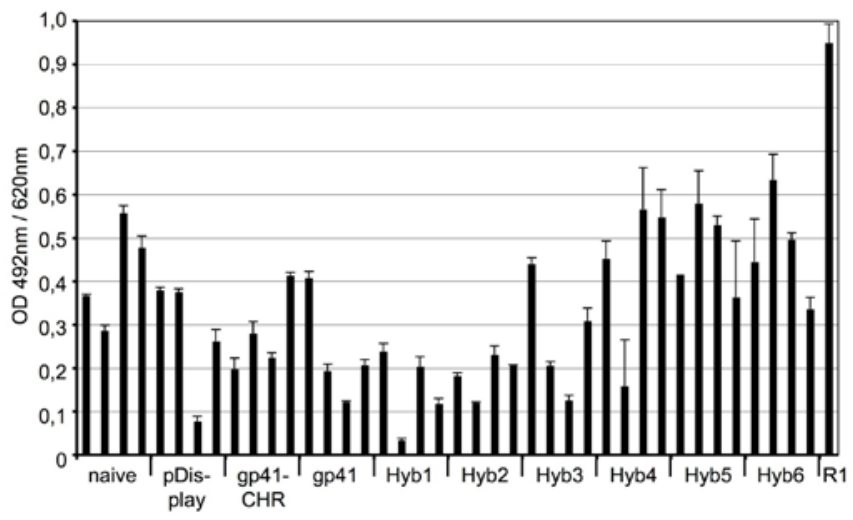

Figure 4: Demonstration of antibodies binding to KoRV p15E in immunised and non-immunised rats by ELISA using $\mathrm{p} 15 \mathrm{E}$ of KoRV as antigen. Sera were tested at 1:500. As positive control a rat serum (R1) specific for p15E of KoRV was used.

interfered with the antibody response against the gp41-derived FPPR and MPER when hybrids were used.

The finding that pre-formed antibodies against p15E exist in newly delivered rats is an interesting finding during these studies. It is likely that the antibodies reacting with p15E of the KoRV represent crossreacting antibodies specific for $\mathrm{p} 15 \mathrm{E}$ of another related retrovirus probably an endogenous rat retrovirus. There are numerous data showing that endogenous retroviruses can be activated during mitogen stimulation of lymphocytes in vitro [43-45] and in immune responses in vivo $[45,46]$. Thus, further studies would be needed to investigate the origin of these pre-existing antibodies.

The present study using a new immunisation approach based on MPER-containing antigens underlines, that a much deeper understanding of the structure of gp41 and the interaction of FPPR and MPER is required to overcome the recent restrictions in the induction of 2F5/4E10-like antibodies.

\section{Acknowledgment}

We would like to thank Annette Dietrich, Nicole Wagner and Kerstin Petsch for excellent technical assistance. The following reagents were obtained through the AIDS Research and Reference Reagent Program, Division of AIDS, NIAID $\mathrm{NIH}$ : HTLV-III $/ \mathrm{H} 9$ from Dr. Robert Gallo, the monoclonal antibody 2F5 from Dr. Hermann Katinger and pNL4-3 from Dr. Malcolm Martin.

\section{References}

1. Muster T, Steindl F, Purtscher M, Trkola A, Klima A, et al. (1993) A conserved neutralizing epitope on gp41 of human immunodeficiency virus type 1 . J Virol 67: 6642-6647.

2. Zwick MB, Labrijn AF, Wang M, Spenlehauer C, Saphire EO, et al. (2001) Broadly neutralizing antibodies targeted to the membrane-proximal external region of human immunodeficiency virus type 1 glycoprotein gp41. J Virol 75: $10892-10905$.

3. Zwick MB (2005) The membrane-proximal external region of HIV-1 gp41: a vaccine target worth exploring. AIDS 19: 1725-1737.

4. McGaughey GB, Barbato G, Bianchi E, Freidinger RM, Garsky VM, et al (2004) Progress towards the development of a HIV-1 gp41-directed vaccine. Curr HIV Res 2: 193-204.

5. Denner J (2011) Towards an AIDS vaccine: The transmembrane envelope protein as target for broadly neutralising antibodies. Hum Vaccin 7: 4-9.

6. Fiebig U, Stephan O, Kurth R, Denner J (2003) Neutralizing antibodies against conserved domains of $\mathrm{p} 15 \mathrm{E}$ of porcine endogenous retroviruses: basis for a vaccine for xenotransplantation? Virology 307: 406-413.
7. Kaulitz D, Fiebig U, Eschricht M, Wurzbacher C, Kurth R, et al. (2011) Generation of neutralising antibodies against porcine endogenous retroviruses (PERVs). Virology 411: 78-86.

8. Langhammer S, Fiebig U, Kurth R, Denner J (2005) Neutralising antibodies against the transmembrane protein of feline leukaemia virus (FeLV). Vaccine 23: 3341-3348.

9. Langhammer S, Hübner J, Kurth R, Denner J (2006) Antibodies neutralizing feline leukaemia virus (FeLV) in cats immunized with the transmembrane envelope protein p15E. Immunology 117: 229-237.

10. Langhammer S, Hübner J, Jarrett $O$, Kurth R, Denner J (2011) Immunization with the transmembrane protein of a retrovirus, feline leukemia virus: Absence of antigenemia following challenge. Antiviral Res 89: 119-123.

11. Fiebig U, Hartmann MG, Bannert N, Kurth R, Denner J (2006) Transspecies transmission of the endogenous koala retrovirus. J Virol 80: 5651-5654.

12. Sun ZY, Oh KJ, Kim M, Yu J, Brusic V, et al. (2008) HIV-1 broadly neutralizing antibody extracts its epitope from a kinked gp41 ectodomain region on the vira membrane. Immunity 28: 52-63.

13. Alam SM, Scearce RM, Parks RJ, Plonk K, Plonk SG, et al. (2008) Human immunodeficiency virus type $1 \mathrm{gp} 41$ antibodies that mask membrane proximal region epitopes: antibody binding kinetics, induction, and potential for regulation in acute infection. J Virol 82: 115-125.

14. Fiebig U, Eschricht M, Schmolke M, Kurth R, Denner J (2009) Mode of interaction between the HIV-1 neutralizing monoclonal antibody $2 \mathrm{~F} 5$ and its epitope. AIDS 23: 887-895

15. Haynes BF, Fleming J, St Clair EW, Katinger H, Stiegler G, et al. (2005) Cardiolipin polyspecific autoreactivity in two broadly neutralizing HIV-1 antibodies. Science 308: 1906-1908.

16. Alam SM, McAdams M, Boren D, Rak M, Scearce RM, et al. (2007) The role of antibody polyspecificity and lipid reactivity in binding of broadly neutralizing antiHIV-1 envelope human monoclonal antibodies $2 \mathrm{~F} 5$ and 4E10 to glycoprotein 41 membrane proximal envelope epitopes. J Immunol 178: 4424-4435.

17. Matyas GR, Beck Z, Karasavvas N, Alving CR (2009) Lipid binding properties of 4E10, 2F5, and WR304 monoclonal antibodies that neutralize HIV-1. Biochim Biophys Acta 1788: 660-665.

18. Lorizate M, de la Arada I, Huarte N, Sanchez-Martínez S, de la Torre BG, et al. (2006) Structural analysis and assembly of the HIV-1 Gp41 amino-termina fusion peptide and the pretransmembrane amphipathic-at-interface sequence. Biochemistry 45: 14337-14346.

19. Bellamy-McIntyre AK, Lay CS, Baär S, Maerz AL, Talbo GH, et al. (2007) Functional links between the fusion peptide-proximal polar segment and membrane-proximal region of human immunodeficiency virus gp41 in distinct phases of membrane fusion. J Biol Chem 282: 23104-23116.

20. Noah E, Biron Z, Naider F, Arshava B, Anglister J (2008) The membrane proximal external region of the HIV-1 envelope glycoprotein gp41 contributes to the stabilization of the six-helix bundle formed with a matching N' peptide. Biochemistry 47: 6782-6792.

21. Buzon V, Natrajan G, Schibli D, Campelo F, Kozlov MM, et al. (2010) Crysta structure of HIV-1 gp41 including both fusion peptide and membrane proximal external regions. PLoS Pathog 6: e1000880.

22. Lay CS, Ludlow LE, Stapleton D, Bellamy-McIntyre AK, Ramsland PA, et al. (2011) Role for the terminal clasp of HIV-1 gp41 glycoprotein in the initiation of membrane fusion. J Biol Chem. 286: 41331-41343.

23. Grundner C, Mirzabekov T, Sodroski J, Wyatt R (2002) Solid-phase proteoliposomes containing human immunodeficiency virus envelope glycoproteins. J Virol 76: 3511-3521.

24. Ofek G, Tang M, Sambor A, Katinger H, Mascola JR, et al. (2004) Structure and mechanistic analysis of the anti-human immunodeficiency virus type 1 antibody 2F5 in complex with its gp41 epitope. J Virol 78: 10724-10737.

25. Huarte N, Lorizate M, Maeso R, Kunert R, Arranz R, et al. (2008) The broadly neutralizing anti-human immunodeficiency virus type 1 4E10 monoclonal antibody is better adapted to membrane-bound epitope recognition and blocking than 2F5. J Virol 82: 8986-8996.

26. Huarte N, Lorizate M, Kunert R, Nieva JL (2008) Lipid modulation of membranebound epitope recognition and blocking by HIV-1 neutralizing antibodies. FEBS Lett 582: 3798-3804. 
Citation: Behrendt R, Fiebig U, Schmolke M, Kurth R, Denner J (2012) Induction of Antibodies Specific for Gp41 of HIV-1 by Gene Gun DNA Vaccination. J Vaccines Vaccin 3:145. doi:10.4172/2157-7560.1000145

27. Lu S, Santoro JC, Fuller DH, Haynes JR, Robinson HL (1995) Use of DNAs expressing HIV-1 Env and noninfectious HIV-1 particles to raise antibody responses in mice. Virology 209: 147-154.

28. Vinne L, Nielsen HV, Bryder K, Corbet S, Nielsen C, et al. (1999) Gene gun DNA vaccination with Rev-independent synthetic HIV-1 gp160 envelope gene using mammalian codons. Vaccine 17: 2166-2175

29. Wild J, Bojak A, Deml L, Wagner R (2004) Influence of polypeptide size and intracellular sorting on the induction of epitope-specific CTL responses by DNA vaccines in a mouse model. Vaccine 22: 1732-1743.

30. Wang S, Arthos J, Lawrence JM, Van Ryk D, Mboudjeka I, et al. (2005) Enhanced immunogenicity of gp120 protein when combined with recombinant DNA priming to generate antibodies that neutralize the JR-FL primary isolate of human immunodeficiency virus type 1. J Virol 79: 7933-7937.

31. Tacke SJ, Bodusch K, Berg A, Denner J (2001) Sensitive and specific immunological detection methods for porcine endogenous retroviruses applicable to experimental and clinical xenotransplantation. Xenotransplantation 8: 125-135.

32. Behrendt R, Fiebig U, Norley S, Gürtler L, Kurth R, et al. (2009) A neutralization assay for HIV-2 based on measurement of provirus integration by duplex realtime PCR. J Virol Methods 159: 40-46.

33. Cassol S, Rudnik J, Salas T, Montpetit M, Pon RT, et al. (1992) Rapid DNA fingerprinting to control for specimen errors in HIV testing by the polymerase chain reaction. Mol Cell Probes 6: 327-331.

34. Luo M, Yuan F, Liu Y, Jiang S, Song X, et al. (2006) Induction of neutralizing antibody against human immunodeficiency virus type 1 (HIV-1) by immunization with gp41 membrane-proximal external region (MPER) fused with porcine endogenous retrovirus (PERV) p15E fragment. Vaccine 24: 435-442.

35. Arnold GF, Velasco PK, Holmes AK, Wrin T, Geisler SC, et al. (2009) Broad neutralization of human immunodeficiency virus type 1 (HIV-1) elicited from human rhinoviruses that display the HIV-1 gp41 ELDKWA epitope. J Virol 83: 5087-5100.

36. Kim M, Qiao Z, Yu J, Montefiori D, Reinherz EL (2007) Immunogenicity of recombinant human immunodeficiency virus type 1-like particles expressing gp41 derivatives in a pre-fusion state. Vaccine 2007 25: 5102-5114.
37. Wang J, Tong P, Lu L, Zhou L, Xu L, et al. (2011) HIV-1 gp41 core with exposed membrane-proximal external region inducing broad HIV-1 neutralizing antibodies. PLoS One. 6: e18233.

38. Ye L, Wen Z, Dong K, Wang X, Bu Z, et al. (2011) Induction of HIV neutralizing antibodies against the MPER of the HIV envelope protein by HA/gp41 chimeric protein-based DNA and VLP vaccines. PLoS One 6: e14813.

39. Zhou M, Kostoula I, Brill B, Panou E, Sakarellos-Daitsiotis M, et al. (2012) Prime boost vaccination approaches with different conjugates of a new HIV-1 gp41 epitope encompassing the membrane proximal external region induce neutralizing antibodies in mice. Vaccine 30: 1911-1916.

40. Kamdem Toukam D, Tenbusch M, Stang A, Temchura V, Storcksdieck M, e al. (2012) Targeting antibody responses to the membrane proximal external region of the envelope glycoprotein of human immunodeficiency virus. PLoS One 7: e38068.

41. Wahome N, Pfeiffer T, Ambiel I, Yang Y, Keppler OT, et al. (2012) Conformationspecific display of $4 \mathrm{E} 10$ and $2 \mathrm{~F} 5$ epitopes on self-assembling protein nanoparticles as a potential HIV vaccine. Chem Biol Drug Des 80: 349-357.

42. Alving CR, Beck Z, Karasavva N, Matyas GR, Rao M (2006) HIV-1, lipid rafts, and antibodies to liposomes: implications for anti-viral-neutralizing antibodies. Mol Membr Biol 23: 453-465

43. Stoye JP, Moroni C (1983) Endogenous retrovirus expression in stimulated murine lymphocytes. Identification of a new locus controlling mitogen induction of a defective virus. J Exp Med 157: 1660-1674.

44. Tacke SJ, Specke V, Denner J (2003) Differences in release and determination of subtype of porcine endogenous retroviruses (PERV) produced by stimulated normal pig blood cells. Intervirology 46: 17-24.

45. Hirsch MS, Phillips SM, Solnik C, Black PH, Schwartz RS (1972) Activation of leukemia viruses by graft-versus-host and mixed lymphocyte reactions in vitro. Proc Natl Acad Sci U S A 69: 1069-1072.

46. Denner J, Dorfman N (1977) Small virus-like particles in leukosis-like syndrome induced by certain antigens and immunostimulators. Acta Biol Med Ger 36 1451-1458. 